\title{
Grüt: A Gardening Sensor Kit for Children
}

\section{A digital application that helps children develop ownership for their plants.}

\author{
Ilaria Zonda \\ Politecnico di Torino \\ Ecodesign \\ Torino, Italy \\ ilaria.zonda@gmail.com \\ MediaLAB Amsterdam
}

\author{
Jarmal Martis \\ Hogeschool van Rotterdam \\ Communication and Multimedia Design \\ Den Hague, The Netherlands \\ jarmal.martis@live.com \\ MediaLAB Amsterdam
}

\begin{abstract}
One of the main problems in modern society is food waste. The main cause of it is the attitude of the consumers, which influence enormously the whole food chain, from production to consumption. Most of buyers see food as a commodity and, especially children, don't have any idea where it comes from. One way to reduce the problem seems to be changing consumers' attitude, which develops during the early years of childhood. Research has shown a change in children's food-related behavior after attending school garden classes. Often the experience of growing crops can't be done in the domestic space, thus causing a loss of the positive effects in the long term. This paper presents a project that tries to teach children how to grow their own food indoor and outdoor, mixing real and virtual reality, connecting something natural as a plant to the Internet of Things (network of physical objects virtually connected to each other and to the web). The use of sensors related to an app makes it more fun and educational. The aim of the project is to change children's attitude towards food, increasing their knowledge about production and consumption in order to reduce waste in the future. The research has been in collaboration with Cisco NL and MediaLAB Amsterdam. The user testing has been executed in Amsterdam, with Dutch children.
\end{abstract}

Keywords: gardening; children; Internet of Things; virtual avatars; the Tamagotchi effect; educational

\section{INTRODUCTION}

In every step of the food chain, starting from production and ending with consumption, there's a waste of edible food [1]. Causes of food waste are uncertainty, attitude, market mechanisms and policy. The project in this paper focuses on the consumers' attitude towards food. A big amount of waste happens in the last part of the cycle, almost $31 \%$ of the food being wasted by consumers after buying it [2]. Buyers have an enormous influence on what happens in the whole food cycle; with their attitude they affect the supply and demand of every product. The urbanization and the globalization of the food industry caused the personal proximity between producer and consumer to be cut out, removing the basis of trust in the production process and the quality of food [3]. In time, this changed consumers' perspective of food: they see food as a commodity rather than a valuable resource. This shift in attitude towards food means that the consumers are more likely to waste food [4]. Gardening has a positive long term effect on children's perception and attitude towards food, developing in them a stronger sense of responsibility, respect, care and environmental awareness [5]. This paper proposes a combined system of sensors and an app that have the goal to help children in the process of growth, giving the necessary support and all the information they need through a virtual avatar. The goal of the project is to extend the experience of school gardens also in private houses, creating in children a stronger bond and awareness towards plants. The paper is organized as follows: Section II explains how the feeling of ownership can influence children's motivation in taking care of something, shows the importance of school gardens in children's education and describes the so called "Tamagotchi Effect". Section III explains the project, describing both the sensors system and the app. Section IV discuss the results of user testing. Section V explains the conclusions and Section VI shows the future work.

\section{BACKGROUND}

\section{A. Children's feeling of ownership}

The state of ownership, or psychological ownership, is defined as the state in which the child feels that an object is his [6]. The feeling of ownership reflects the relationship between the child and an object (material or immaterial) in which the child perceives it as being part of his extended self. The extended self is the sum of all items that the child regards as a part of who they are (limbs, parents, friends, pets, etc.) [7]. Because of this perceived relationship, the kid tends to care for it in the same way he would take care of his own. The most powerful means by which a child invests himself in an object is to create it. Creation requires the child to invest his time, energy and even his values and identity. The created object is attached to the child because it is his product, derives from its being and is formed through his efforts [5]. Ownership over an object answers three important human needs: competence (the feeling of being good at something), self-identity and having a place [8]. At the same time, the needs are also factors that contribute to the child's development of ownership, making it a continuous interaction. Because of this continuous interaction a child reflects on his relationship with the object and develops a sense of responsibility for it. The innate desire 
of being good at something drives a child to explore and interact with items in his environment. This interaction results in the child exercising control on them and gaining a feeling of competence. Being in control of an object comprises a large part of what means to posses it. The possession expresses child's ability to exercise control over his environment, in the same way that his limbs give him the ability to control and shape his surroundings. The more control the child can exercise over an object, the more he associates it with himself developing feelings of ownership over it. By experiencing an interactive process with the object, the child learns more about it establishing and maintaining a sense of identity [7]. Ownership can lead to a child taking responsibility for an object. Responsibility is defined as the habit of choosing, and accepting the consequences of the choice of behavior. In other words, when a kid takes ownership over an object, he chooses to accept the consequences of his behavior (good care or negligence).

There are a few factors that contribute to the development for a child's sense of responsibility. He must:

- Be committed to a task;

- Work at tasks persistently to practice the skill needed to complete them;

- Be internally motivated;

- Have sufficient information to know what is expected of him;

- Have the trust and respect of adults around them;

- Receive the guidance and support of adults when needed [9]

\section{B. School gardens}

Each year 6.000 to 7.000 children aged 9-10 attend a program at a school garden near their school, in the Netherlands. The program that is given was developed by ANMEC (Amsterdam's Centre for Nature and Environmental Education) as part of an initiative to make Nature and Environment classes more practical. The authors interviewed Elena Francissen, a consultant at ANMEC, getting the following information. In summer, when school starts, the children receive theoretical classes where they learn the basics of gardening. At the end of the summer they start attending the school gardens for an hour and a half each week. Each child receives a plot of land with pre-cultured plants to take care of. At the end of the school year the children harvest their plants and at some school gardens get to cook dishes with their harvested plants. ANMEC has conducted a study where they review the children's satisfaction with the school gardening classes. In this study they have highlighted how many children like the program and what they like about it. The study has shown that $64 \%$ of them really like gardening, $21 \%$ have no special feeling either way and $11 \%$ find it boring. $91 \%$ of all the interviewed kids have indicated that they have learned something, 7\% indicated that they have not learned anything and $2 \%$ have not answered. The children who indicated that they find gardening boring were more likely not to have learned anything.

The activities that the children enjoy the most are: gardening (taking care of the plants), the harvest and cooking with the harvested crops. Regardless of their prior knowledge, most children take the care of their plants very seriously. The fact that the plants are given to them results in the children taking responsibility for their plants. This often involves naming the plants or describing the plants as 'their children'.

At the beginning of every trip to the school garden, the children are very excited to check on the progress of their plants. They get annoyed or upset if their plants suffer because of another child's negligence or if an animal eats from their plant and become excited if the plant has done well. Children often are more likely to form a bond with their biggest and/or most beautiful plants. They are less likely to do that with plants that wither or die because they see how well the plants of other children are doing and feel like they have failed. Cooking after the harvest also is a point of pride and great satisfaction for the children. They see the successful growth process and cooking with fruits and vegetables that they harvested themselves as a reward for their efforts. The interview revealed that after the school garden program, most of the children has an interest to continue gardening at home, but they are not always able to do that because of lack of spaces and guidance from their parents [10]. Regarding the sense of ownership, the school garden develops it by giving each child a plant (or more than one) to take care of, but fails in growing the sense of responsibility, because the kids can take care of their plants only once a week. In the amount of time between each visit to the garden someone from the staff takes care of the plants, thus nullifying the cause-effect relationship that better develops responsibility. In the project described in this paper the authors wants to go beyond the school garden experience, creating a one-to-one close relationship and experience between the child and his plant, where everyday needs are important for the plant's wellbeing and the child's education.

\section{The Tamagotchi effect}

While gardening, the children have one goal: to make sure their plants grows well and bear fruits. In order to accomplish this goal, they need to know how to properly take care of their plants. By providing the child with feedback during the plant's growth process, the child has more insight into his behavior and knows what he has to change about his behavior in order to better take care of it [11]. According to Morris Massey [4], a person's values are developed before the age of 21. Up to age 7 a child's mind is like a sponge, absorbing everything around him and accepting much of it as true, especially when it comes from parents. Between the ages of 8 and 13 children start copying other people, including their parents. Instead of blindly accepting the values of others, a child explores and assesses their values, to determine whether he is comfortable with them or not. The figure of reference can be a parent, a teacher, a friend or, as we are about to explain, a virtual companion. The most striking example of a virtual companion that influenced children a lot is Tamagotchi. It used to be a popular game device in the 90's and children tended to develop feelings of ownership for their Tamagotchi pets (the Tamagotchi effect [12]). The goal of the game is to keep the pet alive and entertained. By giving the user a simple interface and clear goals in short intervals (feeding, bathing etc.) and 
easy ways to complete these goals, the Tamagotchi manages to improve the rate in which the user is engaged. Tamagotchi gives the user the experience of owning a virtual pet; the pet goes through several stages of growth and will develop depending on the care the user provides. The user needs to feed, clean and care for the Tamagotchi during its life span. If the user takes good care of the pet, it will be smarter, happier and require less attention as an adult. Should the user not take proper care of the pet, its condition will deteriorate and it will eventually die. Tamagotchi were originally designed for teenage girls to give them an idea of what it would be like to take care of children [13]. However, the Tamagotchi quickly become popular under people of all ages and has sold 76 million units worldwide as of 2010. The Tamagotchi's rise in popularity is due to it's ability to fulfill people's innate desire to take care of something or someone [14] and it has a simple gameplay formula: a mobile experience that the user engages with in several short sessions a day [15]. The popularity of the Tamagotchi in the 90's can be explained because it successfully allows children to take ownership over their digital pet. It does so by making use of all the factors that influence the development of ownership and it is designed in such a way that the amount of errors the user can make is limited. Tamagotchi allows the child to control the creation of the pet: he can pick what kind of pet he wants and give it a name. The Tamagotchi also limits the amount of mistakes the child can make in the growth of the pet. It clearly states beforehand what the needs of the pet are, when the pet needs the child's attention and how he can solve them. This gives the child the feeling that he has control over his pet's growth, which in turn makes him want to spend more time with it, taking the responsibility of its wellbeing and forming a bond with it. The Tamagotchi effect is described as the development of an emotional attachment with both material (machines) and artificial beings (avatars) that otherwise do not have any real emotions [16]. An avatar is an artificial (digital) companion that is an intelligent and cognitive representation of a character, person or object. When a child is asked to care for an avatar he will feel an emotional connection to the avatar and experience it as intelligent, if the child's actions have an influence on the avatar's condition and if the avatar offers feedback on the child's actions [16].

The feedback can be given in the form of emotions that the child can interpret to determine its condition. The emotions expressed can be as simple as a symbol that represents a specific emotion: a heart for happiness or a tear for sadness [17]. For the child to perceive the avatar's emotions as real, it must be based on an internal value system that is adaptive to the avatar's conditions [18]. In the case of the Tamagotchi this was an algorithm programmed into the device that dictated when the pet was hungry or needed to be cleaned.

\section{GRÜT}

\section{A. Ownership and responsibility}

The product developed by the authors tries to answer to all the specific needs required for the child to develop a relationship with his plant, the condition for him to learn how to take care of it. As stated in chapter II (section A), the sense of ownership is achieved when the feeling of competence, identity and having a place are achieved. Giving the child the technical skills and insights for him to be able to succeed in the growth process, is the first step to make him feel competent. The direct connection between the child and the avatar leads to identifying the avatar as a companion, to which the kid can relate and deal with. The possibility of customizing the virtual environment in order to mirror the reality in which the child lives and experiences, answers the need of having a place, in the sense of feeling comfortable, in a real and virtual setting.

Giving daily tasks strengthens the feeling of responsibility. Everyday the child is asked to perform certain actions, in order to keep the plant healthy and the virtual avatar happy. The direct perception of how much the child's actions influence the wellbeing of the plant motivates him in being steady in performing the daily tasks every day.

The presence of a virtual avatar, finally, gives the child a guide, a teacher and a friend, to whom he can relate for insights in the results of caring for the avatar's (and plant's) wellbeing.

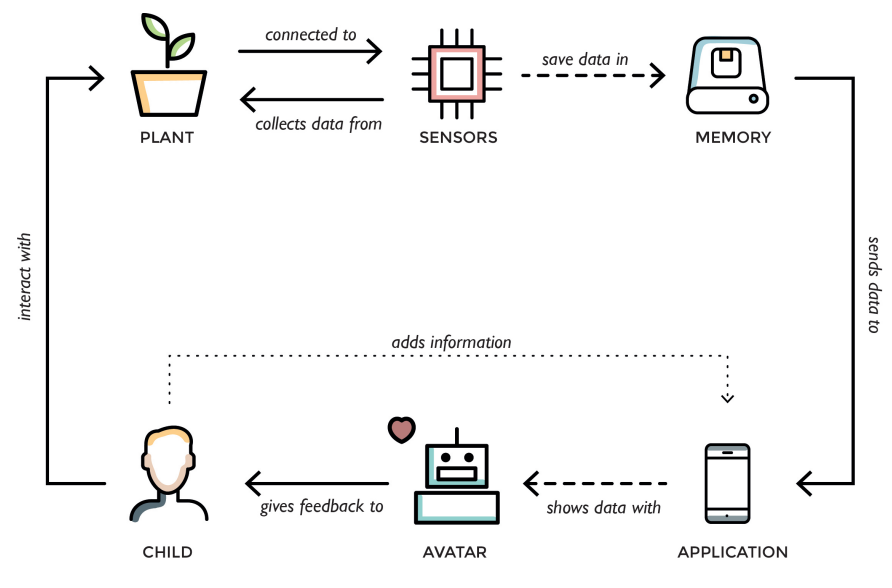

Figure 1. Technical Flow

\section{B. Applying the Tamagotchi effect}

A physical plant, just like a Tamagotchi, has a set of basic factors that determine its growth condition. These factors are: the amount of sunlight it receives, the humidity of the soil and the temperature of the environment [19]. The condition of the plant can be made transparent by measuring the three factors with sensors. The sensors are attached to the soil around the plant and can send the data to the phone; the phone will send the data to the cloud and compares it to the values that are preferred for optimal growth of the plant. Depending on the amount of light, water or heat/cold the plant receives, the avatar will display the proper emotion that mirrors the plant's condition (Figure 1). By using the Tamagotchi effect as gamification element, the digital application can present the data that is gathered in a way that the child is accustomed to (through a game character), and finds fun and interesting. Thus will encourage him to engage more with it. Since a 
physical plant also has needs that determine how well it will grow and as these needs can be transferred to the digital realm, it can be represented in a digital application as an avar.

\section{FRONT SIDE}

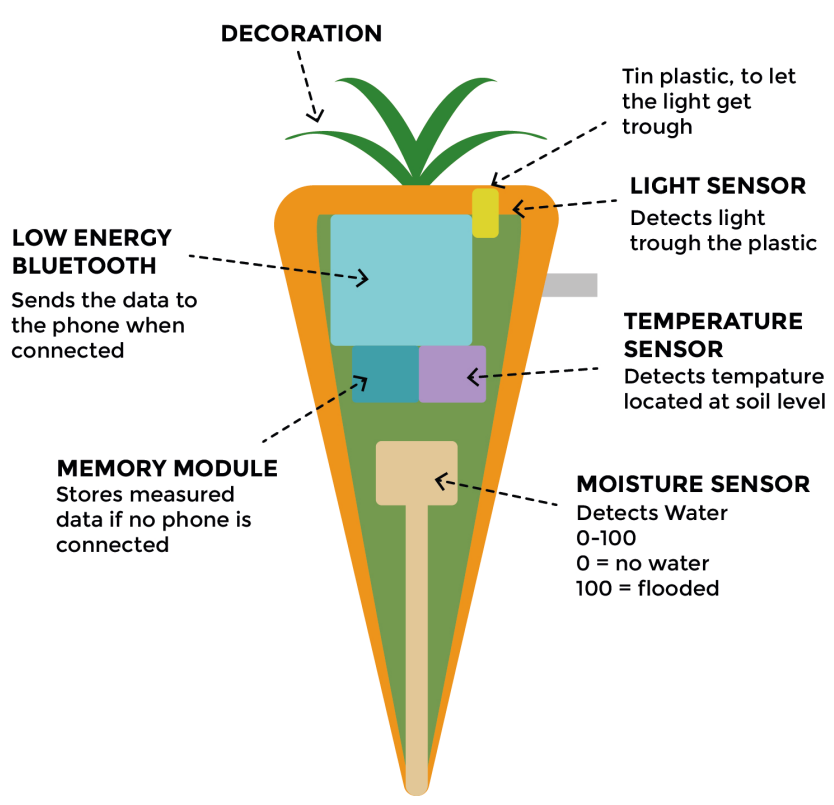

BACK SIDE

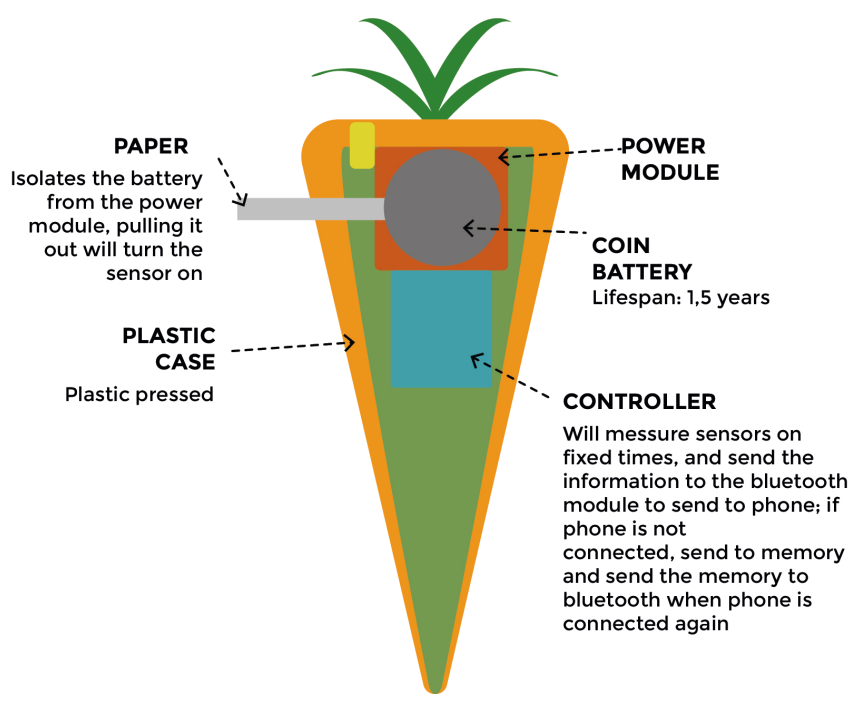

Figure 2. Sensor's technical specifications

\section{Concept}

The product consists of a digital application and a sensor kit. Three sensors compose the sensor kit: temperature, humidity and light. The child puts the kit in the soil next to the seedling. The sensors will send data about the plant's condition to the app, which provides the child with an overview of the plant's condition and advice for the proper care it needs. The primary target audience is children of ages of 9 and 10, who have an interest in gardening but have no or very little experience. The secondary target are parents who want to involve their children more in gardening, but who have no time and/or knowledge to properly do it.

\section{The sensors}

The sensors (light, temperature and humidity) are grouped in a plastic case, which can be customized in its exterior shape. Inside the case there are also a coin battery and a controller that measures sensors on a fixed time, and sends the data to the Bluetooth module, which in turns delivers them to the phone. If the phone is not connected, the data are stored in a small memory, ready to be sent during the first next connection (Figure 2).

\section{The App}

The application must provide the child with insights about the growth process of his seedling, a clear checklist of activities that he has to perform and, most of all, the avatar must automatically react to the kid's interaction with the physical plant.

When the child launches the application for the first time, a small tutorial will run explaining each element on the screen.

Here is a short overview of the app's contents (Figure 3.): 


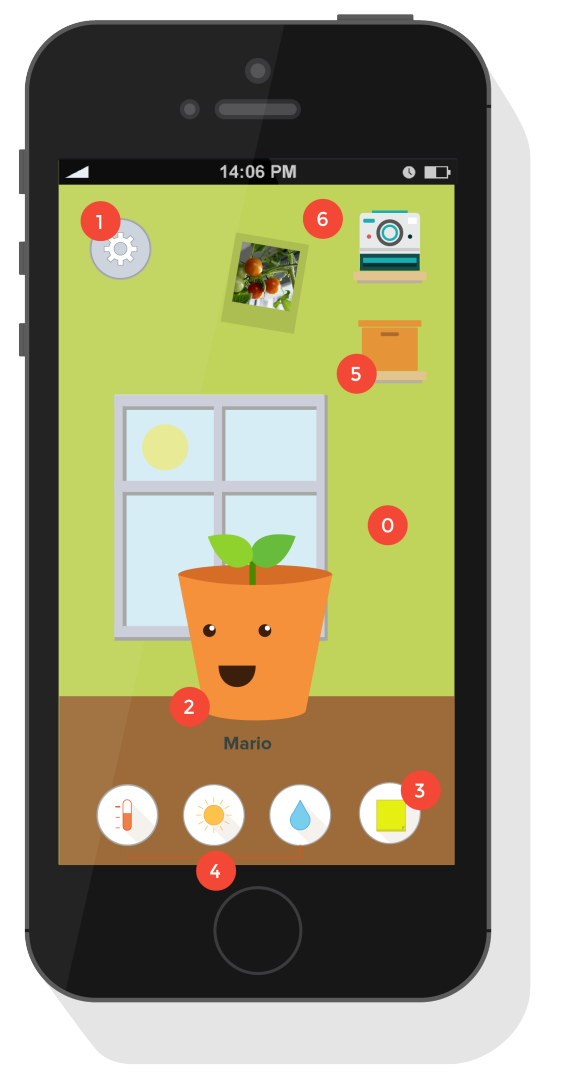

Figure 3. App's interface

0. Environment: Everything on screen is customizable (moveable) and interactive. The light in the room and the weather displayed outside, change according to the time of day and the real climatic conditions. The child can recreate the environment of his own house, where the real plant is.

1. Меnu: The menu hides all the system functions. When the child opens the menu, he can edit his profile, the room/garden currently on screen and change overall system settings.

2. Selected plant: The avatar displays the attitude/ mood of the plant through facial expressions and text bubbles. If the child clicks on the avatar he will be asked to input certain data related to the physical conditions of the plant (amount of leaves, status of the soil and other observations). This data will be used to further determine what actions appear in the to do list, as well as the appearance of the plant and what it will tell and ask the child to do. For example, if a plant has moldy soil and some brown leaves, the checklist will add the following item "trim brown leaves with scissors". The avatar will appear with some brown leaves. By clicking on it, the plant will also explain how mold affects it, how it's formed and how it can be prevented. Once the leaves are trimmed, and the mold removed the child has to input this changes and the avatar will change its appearance in a happier mood. If the child takes proper care of the plant and gives it attention (by going through the checklist every day and filling in the virtual plant's questions) the avatar will be happy and have a positive attitude towards the child, thanking him for his efforts. If not the avatar will start getting grumpier and get a negative attitude. The changes in the avatar are immediate after the inputs, to display the strict relation between actions and consequences.

As the real plant grows, the avatar will grow with it. A small plant is portrayed as a baby pot, and the bigger the plant gets, the bigger the avatar gets, to the point that it will start getting flowers and fruit. The plant will also tell the child educational stories. These stories are narrated by the plant, shown in animations in a text bubble above the plant's head and cover topics that are related to the plant's growth.

The stories are kept intentionally short, so the information can be dosed out into smaller bits and the child won't get bored or it won't lose his attention. As the days pass the plant will go more in depth. In this manner the plant will educate the child about its needs and wants and the child will better understand how the plant grows and why it behaves the way it does.

3. To Do List: The to do list gives an overview of all the actions the child must complete on a given day. It is divided into daily tasks and big tasks. The daily tasks consist of basic tasks the child can do every day: making sure the plant has enough light, water, temperature and listening to the plant's day. These tasks can automatically be checked off by the application. Through the sensors, the app can track the light water and temperature. The big tasks can be checked off by the child after he has performed them. By tracking the to do list, the application can also tell whether the list item can be checked off or not. All list items have a question mark at the end, that the child can click if he needs more information about how to perform them. When clicked, the plant will give a brief explanation about the specific task. If the child does not perform a task, the application will take note. The more the child neglects the plant, the grumpier it will get. The more the child keeps track of the plant's progress and performs tasks in the to do list, the happier the plant will be and the more will show affection towards his owner.

4. Status stickers: The status stickers give a quick overview if the plant is receiving too much or too little light, water and the quality of the environmental temperature.

When the plant is added to the room, its status will be shown on the stickers under the bookcase and a to do list will be generated based on data gathered by sensors and the child's observations. The plant also displays his status through its mood (expressions \& text bubbles).

5. The Box: The cardboard box adds other features to the app: the encyclopedia and the recipes book. The first is the knowledge base where children and parents can find all the information they need about plant's growth, displayed through videos and illustrations, to be easy to understand and fun.

The recipes book shows recipes that are related to the plants that the child is growing, giving insights for a conscious consumption.

6. Polaroids: The child can add pictures to the wall by 
clicking on the Polaroid camera. The Polaroids themselves are draggable. This allows the child to make the interface more personal. It will also be possible to share the pictures in the main social networks.

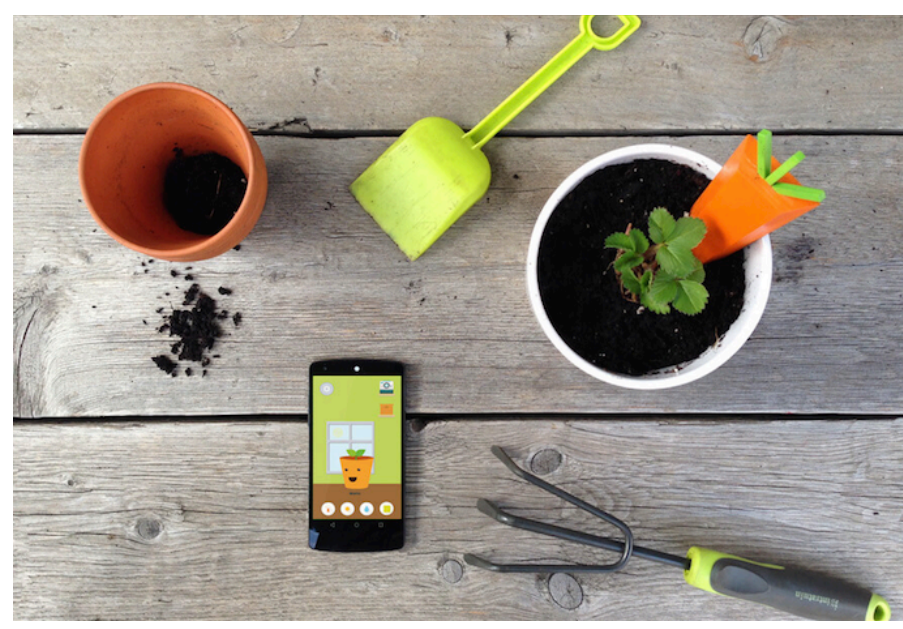

Figure 4. The sensor's mockup and the App

\section{USER TESTING}

The first clickable prototype product was tested with four children, aged 9-10, and their parents. To test the App the team used a potted plant, with a mockup sensor (Figure 4.) attached to it and an iPad with the application prototype on it as visual aids to explain the concept and how the app functioned. After explanation, the participants received a list of task to complete and questions to answer. Based on the ease of which they completed the task and where they struggled, the strong and weak points of the interface were determined.

The tasks and questions were:

Add a plant to the garden;

Determine the mood of the plant;

Explain what the elements on the screen are;

Determine the condition of the plant;

Does the plant have enough water?

- Is the plant receiving enough sunlight?

- Is the plant at the right temperature?

- Do you know how to properly care for a plant?

- If this plant was yours, would you take care of it?

- How often would you check on your plant?

Adding a plant to the garden went smoothly, they did not encounter any problems with the form, they immediately referred to the avatar to confirm the status of the plant (it is the first thing they notice when they open the application), and the intentions of the buttons were clear (Figure 5.).

All of them intuitively solved problems. When the avatar stated that it was too cold, they went to put the plant near the heater so it received more warmth; their first reaction was not to refer to the status buttons for help. They automatically started clicking around the interface to see what was interactive and what was not and in that way discovered the status pop-ups. The status pop-up was clear in it's purpose: to provide extra help if that was needed.

The prototype tested at the beginning differed from the final one by having only the status stickers, which showed the situation of light, temperature and humidity. The avatar showed a limited variety of emotions: very happy, normal, sad, dead. All of the children responded very positively to the avatar and could easily interpret the state of the plant based on the mood the avatar expressed. However, a longer user test has revealed that the avatar was getting "boring" after a few days of use due to it only expressing very basic emotion. The avatar was very monotone and this monotony makes the interactions the child has with his plant less meaningful to him. Regarding the design, they found it very functional but not really fun, in the long term.

After the first user test the new functionalities were added (avatar inputs, Polaroids, editable background, to do list, etc.) and the application was tested again with the same children, who responded very positively towards the redesign. They found the first design more functional and they liked that the new redesign maintained the functionality, but was more playful.

They liked how the checklist and the avatar influenced each other. One of the children found it useful to have a checklist with activities he could do daily because he would often forget or would not know what he had to do. And he also liked that the plant (avatar) would explain things to him if he didn't know what he had to do. The parents liked how educational the application is, but without looking like a "homework assignment". The tasks on the to do list were pretty simple and they felt that their children would be able to do them on their own for the most part, especially since they got help from the app. They also felt that the simplicity of the application was a plus; children didn't have to enter a lot of difficult data and the items on the checklist were simple and straightforward. The children felt that giving the plant some personality would really help in giving them the motivation to care for it. Parents also liked that the application had an encyclopedia built in with videos and text. They felt it was a handy functionality to have considering they didn't know much about growing plants.

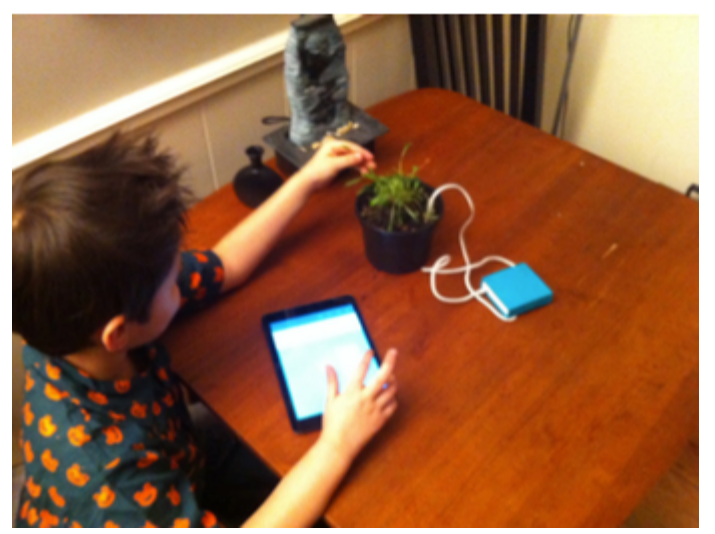

Figure 5. User testing 


\section{CONCLUSIONS}

The user tests have shown that by using the online avatar as a representation of the physical plant, a child has more incentive to care for his plant because the plant's needs are made clear and the child feels like he has more control over the growth of his plant. Giving the plant a personality also acts as extra incentive to motivate the child to use the application every day through the checklist.

Parents also feel more involved because they receive notifications when the child forgets or is not taking proper care of his plant and the knowledge base provides them with all the information they need. The combination of features in the application makes it possible for the child to gain control over the growth of his plant, allows him to spend more time with it and, by doing so, develops a relationship (through the avatar). By addressing these needs, the application stimulates the child to develop ownership for his plant.

\section{FUTURE WORK}

While the clickable prototype has made it possible to generate many insights, it also has its limitations. The application could not be tested during the whole growth process of a plant because of a lack of time, the avatar could not display more than a few states and the checklist could not be tested to its full extent because it still needed to be designed. This did make it difficult to gain insight into what problems and opportunities would arise if the child uses the application for longer periods of time.

In order to gain more insight into how the application will influence the development of ownership in the long term, a fully functioning application must be built in the next iterations of the products.

\section{Technical implementation}

The priority must be to technically implement the clickable prototype. This makes it possible to test the application during a whole growth cycle of a plant and in turn provide insight into weaknesses and opportunities for the application.

\section{Sensors}

In order to support a large number of plants, the application must be developed with data on the requirements needed for each plant to grow properly. There are many on market commercial sensors that can be used for that purpose, and they already have a library with the needs for specific species. This kind of information is necessary to improve the educational aspect of the product, giving the child different results and instructions strictly related to the type of plants they are growing.

\section{Food waste}

The next iterations of the prototype must also explore opportunities to influence the child to waste less food during the whole lifecycle (production, consumption, recycling).
The goal is to give children options for the use of every part of their plant (seeds for replanting, leftovers for composting etc.) and teach them to choose to grow particular plants strictly connected to seasons and geographical area.

Reward systems

The concept as a whole can also benefit by implementing reward systems. By having tiers in the different plants that children can own, it is possible to ease them into gardening by giving them easy plants that grow quickly (like strawberries) first and later on, as they get better and better, they are rewarded by unlocking higher level plants that require more care and patience. This concept of rewarding can also be applied in the editable and customizable background: the more you take good care of your plant, the more you can change the virtual room, color of the pot, etc.

Social networking

The app can create a network of children growing plants, encouraging them to share their products, meet in the real life and interact. These will improve their social interactions and will teach them to manage their outputs sharing instead of wasting them.

Many other sensors and monitoring systems for plants already exist in the commercial field, but they are mostly used for big crops and cultivations, providing very technical data and graphs. The innovative aspect in Grüt project is the educational insights, the emotional involvement provided by the virtual avatar and the simplicity of the data, all of them easier and funnier for kids to understand.

\section{ACKNOWLEDGMENTS}

Special thanks to Gijs Gootjes and Marco van Hout from MediaLAB Amsterdam for the continuous help and support; Rob Boerman, Evelien A1, Iain Kettles, Tamara Pinos, Rinke van Couwelaar for the technical work and all the students at MediaLAB Amsterdam for the many constructive suggestions.

\section{REFERENCES}

[1] FoodDrink Eu, "Preventing food wastage in the food and drink sector",http://www.fooddrinkeurope.eu/uploads/publications_docume nts/Preventing_food_wastage_in_the_food_and_drink_sector.pdf

[2] Circle Economy, "Circle Scan: Current state and future vision, Agri \& Food sector.”, https:/www.rabobank.com/nl/images/03-07_CE_ Rabobank_AgriFood_Circle_Scan.pdf, 2014.

[3] M. Fonte, "Food Systems, Consumption Models and Risk Perception in Late Modernity" International Journal of Sociology of Agriculture and Food, Issue 1, vol. 10, pp. 13-21, 2002.

[4] J. Kearney, "Food consumption trends and drivers.", in Philosopical transaction of the royal society B, vol. 365, no. 1554, August 2010.

[5] R. Passy, M. Morris and F. Reed, "Impact of school gardening on learning: final report submitted to the royal horticultural society." London RHS, 2010.

[6] K. Dirks, J. Pierce, and T. Kostova, "The state of psychological ownership: Integrating and extending a century of research", Review of General Psychology, vol. 7, no. 1, pp. 84-107, March 2003.

[7] R. Belk, W. Belk, "Possessions and the Extended Self", The Journal of Consumer Research, vol. 15, no. 2, pp. 139-168, September 1988. 
[8] H. Dittmar, "The social psychology of material possessions: To have is to be." Hemel Hempstead and St Martin's Press, New York, Journal of Economic Psychology, Elsevier, vol. 14(2), pp. 453-454, June 1992.

[9] D. Harris, and B. Mitton, "The development of responsibility in children.” The Elementary School Journal, vol. 54, no. 5, pp. 268277, January 1954.

[10] E. Francissen, Consultant at ANMEC, http://www.anmec.nl , 2014

[11] S. Hermsen and R. Renes, "Ontwerpen voor Gedragsverandering" Publication Centre of Expertise Creative Industry Utrecht, Utrecht University, 2014.

[12] A. Holzinger, A. Pichler, W. Almer and H. Maurer, "TRIANGLE: A Multi-Media test-bed for examining incidental learning, motivation and the Tamagotchi-Effect within a Game-Show like Computer Based Learning Module", C. Montgomerie \& J. Viteli (Eds.), Proceedings of World Conference on Educational Media and Technology, Association for the Advancement of Computing in Education (AACE), pp. 766-771, 2001.

[13] "Finding companionship in a digital age." Next Generation Magazine, 1997 ,

[14] R. Deyes, "The Tamagotchi craze and virtual reality - The search for novel forms of entertainment." The Mad Scientist Network, Washington University School of Medicine, St. Louis, Missouri, USA, 1998.

[15] M. Helgeson, "How Tamagotchi changed the world." Gameinformer: http://www.gameinformer.com/b/features/ archive/2012/07/27/howtamagotchi-changed-the-world. Aspx , 2012.

[16] J. Brockman, "Digerati: Encounters with the cyber elite.", Hardwired, first edition, October 1996

[17] C. Breazeal, "Designing sociable machines." The MIT Press, 2002.

[18] C. Cañamera, "Emotion understanding from the perspective of autonomous robots research.", Neural Network, vol. 18(4), pp. 445 55, May 2005.

[19] Usda, United States Department of Agriculture, http://www.usna.usda.gov/Gardens/requirements.html 